\title{
Intraguild predation influences oviposition behavior of blow flies (Diptera: Calliphoridae)
}

\author{
Luciane A. Galindo ${ }^{1} \cdot$ Rafael A. Moral ${ }^{2}$ Thiago C. Moretti ${ }^{3} \cdot$ Wesley A. C. Godoy ${ }^{4}$. \\ Clarice G. B. Demétrio ${ }^{2}$
}

Received: 28 November 2015 / Accepted: 5 February 2016 /Published online: 18 February 2016

(C) Springer-Verlag Berlin Heidelberg 2016

\begin{abstract}
The objective of the present study was to determine whether blow flies (Diptera: Calliphoridae) are able to identify larvae of an intraguild predator species in the substrate and avoid laying eggs there. Blow flies oviposited in traps with different treatments: substrate only and substrate with larvae of Chrysomya albiceps (Wiedemann, 1819), Chrysomya megacephala (Fabricius, 1794), or Chrysomya putoria (Wiedemann, 1830). Ch. megacephala, Ch. putoria, and Lucilia eximia (Wiedemann, 1819) avoided laying eggs in the trap containing Ch. albiceps larvae. Cochliomyia macellaria (Fabricius, 1775) did not oviposit differently in each substrate but had overall low abundance. The prevalence of species on corpses may be influenced by the ability of the species to detect the presence of other species, mainly predators. In this sense, intraguild predation may result in misinterpretations of a crime scene and should be considered when assessing the minimum postmortem interval.
\end{abstract}

Wesley A. C. Godoy

wacgodoy@usp.br

1 Departamento de Parasitologia, Instituto de Biociências, Universidade Estadual Paulista Júlio de Mesquita Filho (UNESP), Botucatu, SP, Brazil

2 Departamento de Ciências Exatas, Escola Superior de Agricultura Luiz de Queiroz, Universidade de São Paulo (USP), Piracicaba, SP, Brazil

3 Departamento de Biologia Animal, Instituto de Biologia, Universidade Estadual de Campinas (UNICAMP), Campinas, SP, Brazil

4 Departamento de Entomologia e Acarologia, Escola Superior de Agricultura Luiz de Queiroz, Universidade de São Paulo (USP), Piracicaba, SP, Brazil
Keywords Avoidance behavior · Blow fly ecology · Cannibalism · Chrysomya albiceps $\cdot$ Chrysomya megacephala $\cdot$ Chrysomya putoria

\section{Introduction}

Blow flies (Diptera: Calliphoridae) cause myiases and may carry pathogenic organisms that cause diseases in humans and animals (Moretti and Godoy 2013; Thyssen et al. 2014; Abdel-Hafeez et al. 2015). They are also used in forensic analyses (Wolff et al. 2001; Grassberger et al. 2003; Benecke 2008; Reibe et al. 2010) and in maggot debridement therapy (El-Tantawy 2015).

Interspecific interactions in blow flies result from complex biological processes, which involve specific behaviors that influence the abundance and the diversity of insects in decomposing organic substrates (Faria et al. 1999; Rosa et al. 2006; Rezende et al. 2014). The presence of species with strong interactive attributes (i.e., predators, competitors, and parasitoids) may substantially affect the composition of insects inhabiting vertebrate carrion (Grassberger et al. 2003).

Several kinds of trophic interactions, such as intraguild predation (IGP), take place in communities of necrophagous insects, as in any other complex ecological systems (Rosa et al. 2006). Intraguild predation is the predatory action between competitors belonging to the same guild, which is a group of insects that uses the same type of resource in a similar way (Root 1967; Polis et al. 1989). Two phylogenetically closely related blow fly species, Chrysomya albiceps (Wiedemann, 1819) and Chrysomya rufifacies (Macquart, 1844) (Diptera: Calliphoridae), display this predatory habit during the larval phase. In Brazil, Ch. albiceps was introduced along with other species of the same genus, Chrysomya megacephala (Fabricius, 1794) and Chrysomya putoria 
(Wiedemann, 1830), in 1975 and 1976, contemporaneously with the arrival of large numbers of refugees from Angola and Mozambique (Guimarães et al. 1978; Thyssen et al. 2014). The introduction of these species coincided with the decline of populations of native blow fly species, such as Cochliomyia macellaria (Fabricius, 1775) and Lucilia eximia (Wiedemann, 1819) (Guimarães et al. 1978; Silva et al. 2003).

The intraguild predation behavior of blow flies has been systematically investigated in the laboratory, but rarely in the field (Faria et al. 1999; Rosa et al. 2006). In a laboratory study on the oviposition behavior of two species of intraguild prey (Ch. megacephala and L. eximia) and one intraguild predator (Ch. albiceps), Gião and Godoy (2007) found that intraguild prey species preferred to lay eggs in substrates where no Ch. albiceps larvae were present.

The observations by Gião and Godoy (2007) relate directly to the dynamics of ecological succession on vertebrate carrion. If adult female blow flies can identify and avoid substrates where predatory larvae are present, then it is likely that the attendance by certain species of calliphorid flies will influence the subsequent distribution of necrophagous species on carcasses. Whenever non-predatory species were present in the substrate, prey species continued to use the substrate for oviposition (Gião and Godoy 2007). If this assumption is valid, then the intensity of interspecific interactions, mainly those among species involved in intraguild predation, may be reduced (Rosa et al. 2004).

Understanding the mechanisms of the oviposition behavior, mainly the selection of substrates, is crucial. In many biological systems, the selection of the habitat determines the context of individual interactions, affects the abundance and distribution of local populations, and influences the assemblage and maintenance of communities and ecosystems (Yang 2006).

Motivated by the lack of studies on intraguild predation in calliphorid flies performed in the field with natural populations, we aimed to determine which type of phenomenon modulates the oviposition of these insects, as well as to describe the preypreference or predator-avoidance relationships.

\section{Material and methods}

Adult specimens of Ch. albiceps, Ch. megacephala, and Ch. putoria were collected in the vicinity of the Department of Parasitology of the São Paulo State University, city of Botucatu, São Paulo state, Brazil (22 $52^{\circ} 09^{\prime \prime}$ S, 48 $26^{\prime} 42^{\prime \prime}$ W), in order to obtain the larval populations needed for the experiment. The flies were maintained in nylon-coated cages $(30 \times 30 \times 30 \mathrm{~cm})$, under controlled conditions $\left(25 \pm 1{ }^{\circ} \mathrm{C}\right.$, $70 \% \mathrm{RH}$, and $12 / 12 \mathrm{~h}$ light/dark cycle), and received water and sugar ad libitum. Females were fed beef liver as a supplementary protein source to allow them to complete their gonotrophic cycle (Linhares 1988; Thyssen et al. 2014). The eggs obtained from each species were placed in vials $(5 \mathrm{~cm}$ in height and $5 \mathrm{~cm}$ in diameter) containing $50 \mathrm{~g}$ of fresh ground beef and maintained in the same environmental conditions mentioned above; after hatching, 1st instar larvae were transferred to the traps. As soon as the larvae were added, the traps were exposed once a month in the same place where the adult flies were collected, from July 2006 through June 2007. The meteorological data used in this study were obtained from the Meteorological Unit of the College of Agricultural Sciences of the São Paulo State University (UNESP), Botucatu Campus $\left(22^{\circ} 50^{\prime} 48^{\prime \prime} \mathrm{S}, 48^{\circ} 26^{\prime} 06^{\prime \prime} \mathrm{W}, 786 \mathrm{~m}\right.$ a.s.1.). The distance between the weather unit and the collection site is approximately $10 \mathrm{~km}$. According to the Köppen Classification, the city of Botucatu has a Cfa climate - humid subtropical, with a warm rainy summer and a relatively dry winter. The mean temperature in the warmest and coldest months are 23.1 and $17.1^{\circ} \mathrm{C}$, respectively (Cunha and Martins 2009).

Treatments consisted of substrates with $100 \mathrm{~g}$ of ground beef only (control-TC) and ground beef with 100 1st instar larvae of Ch. albiceps (TCA), Ch. megacephala (TCM), or Ch. putoria (TCP).

In each of the 12 trap setups ( 1 per month), we used 16 (4 treatments and 4 replicates) transparent plastic vials (each $12 \mathrm{~cm}$ in height and $10 \mathrm{~cm}$ in diameter), with small holes in the cover and in the bottom to allow the flies to enter and water to drain, respectively (Fig. 1). The traps were suspended in trees on the same day and remained exposed at the study site for four consecutive days in each month. Each of the traps was suspended by a cord from a tree branch, $180 \mathrm{~cm}$ above the ground. Each tree, $20 \mathrm{~m}$ apart at the collection site, received one set of replicates (4 traps, 1 per treatment). The distance between the four traps in each tree was negligible, so they were approximately under the same light and weather conditions. During the 4 days of exposure, all the traps were inspected twice a day (at 1000 and 1700 hours) for the presence of new eggs or, in the case of Sarcophagidae, 1st instar larvae. All of these were collected during these two daily inspections and taken to the laboratory. All the eggs collected from the traps were placed in vials, and, after they hatched, the larvae were fed with ground beef. As for the 1st instar larvae of flesh flies collected, they were also placed in vials and fed with ground beef. When they reached the adult stage, they were identified to species level (based on Mello 2003), counted, and separated into six groups: Ch. albiceps, Ch. megacephala, Ch. putoria, C. macellaria, L. eximia, and "other species." Oviposition was, therefore, quantified based solely on the number of flies obtained from the laboratory-reared larvae. After the 4 days of exposure, the traps were removed from the field.

Monthly data were pooled into one analysis of the total counts because the interest here was not to describe the fluctuations through time, but to analyze the total number of eggs laid. The data consisted of counts of insects and showed wide 


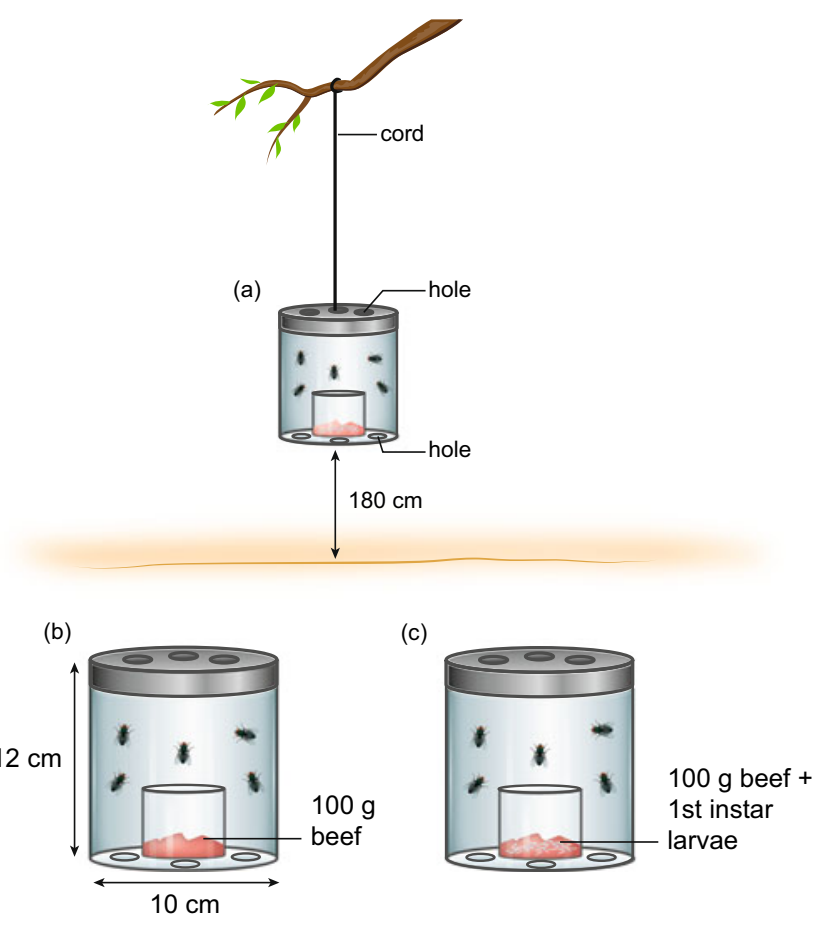

Fig. 1 Trap used in the experiments

variability. A quasi-Poisson generalized linear model was fitted to the data, and the goodness-of-fit was assessed using half-normal plots with simulated envelopes (Demétrio et al. 2014). The linear predictor included the main effects of trap and species as well as an interaction between trap and species effects, and an analysis of deviance table was obtained. Multiple comparisons were performed by obtaining the $95 \%$ confidence intervals for the linear predictors. A principal component analysis was also performed, and a biplot was generated. All analyses were carried out using the R software (R Core Team 2015).

\section{Results and discussion}

Calliphoridae, Muscidae, Fanniidae, and Sarcophagidae were the most numerous families, which is in accordance with various surveys performed in different geographical areas of Brazil (Souza and Linhares 1997; Pujol-Luz et al. 2006; Moretti et al. 2008; Oliveira and Vasconcelos 2010; Moretti and Godoy 2013; Nassu et al. 2014; Oliveira et al. 2015).

Of the dipterans reared in the laboratory during the experiment $(n=163,499)$, the most abundant species was Ch. megacephala, with 112,640 specimens. The intraguild predator Ch. albiceps accounted for 20,717 specimens; also, 4250 individuals of Ch. putoria, 1483 specimens of L. eximia, and only $338 C$. macellaria specimens were reared. A total of 24,071 specimens belonging to "other" species were also reared, including fleshflies (Sarcophagidae); other species of
Lucilia; and members of Fanniidae, Muscidae, and Piophilidae (Table 1).

The larvae present in the traps before their exposure in the field were able to feed on the substrate used for bait. Therefore, fewer eggs/larvae were expected to be found on TCA, TCM, and TCP (compared to TC) because less food was available to attract female flies. Because this condition was common to all sets of replicates, it is not a source of bias. On the other hand, because the distance between the traps in the same tree was insignificant, we cannot ignore the possible occurrence of cross-effects between traps.

The analysis of deviance indicated a significant effect $\left(F_{15}\right.$, $\left.{ }_{72}=2.21, p=0.0134\right)$ of the interaction between the treatments and the species. Ch. megacephala was the most abundant species within each treatment and was found in lowest numbers in TCA (Table 2), showing that it avoids the intraguild predator.

Ch. putoria and the native species $L$. eximia were less abundant but showed the same avoidance behavior (Table 2). Ch. albiceps also showed this avoidance behavior. The native species C. macellaria did not oviposit differently in each substrate (Table 1).

The principal component analysis also confirmed that the species avoided TCA, given the negative correlation of TCA with all other treatments and species (Fig. 2). This suggests that female blow flies possess mechanisms that enable them to perceive a previous occupation of the substrate, as well as which species has previously occupied it. These mechanisms involve not only olfactory and visual cues but also chemical signals, produced either by microbes found on dipteran eggs or by other organisms colonizing the medium (Tomberlin et al. 2011; Zhang et al. 2013; Oliveira et al. 2015). These mechanisms are also involved in the avoidance of oviposition in the presence of Ch. albiceps, given that it is a predator in the larval phase (Faria et al. 1999). This could be expected for the Chrysomya species, as they coevolved on the African continent.

Because Ch. albiceps has been present in Brazil for only about 40 years, the native species may not yet have been completely selected to avoid oviposition in substrates with the predator larvae. Even so, the native species seemed to avoid TCA as well (Table 2, Fig. 2). Given that Ch. albiceps is an intraguild predator, one could expect that it would tend to oviposit in a previously occupied substrate, in order to use the larvae as resource for its own brood (Rosa et al. 2006). However, the highest oviposition rates of Ch. albiceps were in TC and in TCM.

Ch. albiceps tends to arrive on carrion baits earlier than other calliphorid species. However, this rapidity in reaching carrion seems to be more common for large than for small pieces of carrion (Moretti and Godoy 2013).

It is likely that $C h$. albiceps avoids its own larvae since the larger larvae may act as cannibals (Faria et al. 2004). The role 
Table 1 Hatching count (mean $\pm \mathrm{SD}$ ) of each treatment by species

\begin{tabular}{|c|c|c|c|c|c|c|c|}
\hline \multirow[t]{2}{*}{ Treatment } & \multirow[t]{2}{*}{ Replicate } & \multicolumn{6}{|l|}{ Species } \\
\hline & & Ch. albiceps & Ch. megacephala & Ch. putoria & L. eximia & C. macellaria & Other $^{\mathrm{a}}$ \\
\hline \multirow[t]{4}{*}{$\mathrm{TC}$} & 1 & 2012 & 8223 & 277 & 417 & 86 & 1485 \\
\hline & 2 & 1552 & 11,397 & 168 & 302 & 45 & 2156 \\
\hline & 3 & 1980 & 8130 & 455 & 113 & 0 & 1436 \\
\hline & 4 & 2515 & 9402 & 286 & 59 & 0 & 1125 \\
\hline \multirow[t]{4}{*}{ TCA } & 1 & 1136 & 1353 & 102 & 0 & 0 & 2187 \\
\hline & 2 & 1196 & 2702 & 0 & 7 & 0 & 1118 \\
\hline & 3 & 409 & 4427 & 57 & 67 & 68 & 1078 \\
\hline & 4 & 1009 & 3659 & 53 & 0 & 0 & 821 \\
\hline \multirow[t]{4}{*}{ TCM } & 1 & 670 & 8127 & 713 & 167 & 0 & 1115 \\
\hline & 2 & 2051 & 7917 & 414 & 0 & 0 & 1531 \\
\hline & 3 & 1061 & 8230 & 193 & 31 & 2 & 1628 \\
\hline & 4 & 2256 & 5899 & 325 & 140 & 0 & 1102 \\
\hline \multirow[t]{4}{*}{ ТCP } & 1 & 449 & 5913 & 386 & 45 & 0 & 1729 \\
\hline & 2 & 1123 & 12,574 & 456 & 130 & 137 & 2179 \\
\hline & 3 & 882 & 8380 & 324 & 1 & 0 & 1215 \\
\hline & 4 & 416 & 6307 & 41 & 4 & 0 & 2166 \\
\hline
\end{tabular}

TC: control (100 g ground beef only); TCA: $100 \mathrm{~g}$ ground beef + 100 larvae of Ch. albiceps; TCM: $100 \mathrm{~g}$ ground beef +100 larvae of Ch. megacephala; TCP: $100 \mathrm{~g}$ ground beef +100 larvae of Ch. putoria

${ }^{a}$ Comprises other species of Lucilia, Fanniidae, Muscidae, Piophilidae, and Sarcophagidae

of Ch. albiceps in regulating the densities of other flies has been emphasized in studies of population dynamics and also of the succession of insects on vertebrate carrion (Grassberger et al. 2003; Serbino and Godoy 2007).

The oviposition rate of Ch. megacephala was significantly higher than the rates shown by the other species, which may reveal that the species have a stronger preference for the bait than the other species. Obviously, it might also mean that
Ch. megacephala was the first species arriving on the baits or even that the species is simply more abundant in the studied area. Nonetheless, this ability may help to explain its great success following its initial invasion into Brazil; it is abundant in both urban and suburban areas in South America (Wells 1991).

Mean $( \pm \mathrm{SD})$ values for temperature $\left({ }^{\circ} \mathrm{C}\right)$, relative humidity $(\%)$, and rainfall $(\mathrm{mm})$ at the collection site were, respectively: $21.48 \pm 2.23,75.88 \pm 8.02$, and $98.07 \pm 113.91$. The monthly
Table 2 Multiple comparisons between treatments within each species and species within each treatment

\begin{tabular}{lllll}
\hline Species & \multicolumn{4}{l}{ Treatment } \\
\cline { 2 - 5 } & TC & TCA & TCM & TCP \\
\hline Ch. albiceps & $2007.25 \pm 202.90 \mathrm{bA}$ & $937.50 \pm 180.43 \mathrm{bB}$ & $1509.50 \pm 382.58 \mathrm{bAB}$ & $717.50 \pm 171.87 \mathrm{cB}$ \\
Ch. megacephala & $9288.00 \pm 760.27 \mathrm{aA}$ & $3035.25 \pm 662.51 \mathrm{aB}$ & $7543.25 \pm 551.94 \mathrm{aA}$ & $8293.50 \pm 1525.97 \mathrm{aA}$ \\
Ch. putoria & $296.50 \pm 59.25 \mathrm{cA}$ & $53.00 \pm 20.87 \mathrm{cB}$ & $411.25 \pm 110.35 \mathrm{cA}$ & $301.75 \pm 91.00 \mathrm{cA}$ \\
C. macellaria & $32.75 \pm 20.68 \mathrm{cA}$ & $17.00 \pm 17.00 \mathrm{cA}$ & $0.50 \pm 0.50 \mathrm{dA}$ & $34.25 \pm 34.25 \mathrm{cA}$ \\
L. eximia & $230.25 \pm 78.38 \mathrm{cA}$ & $18.50 \pm 16.25 \mathrm{cB}$ & $84.50 \pm 40.71 \mathrm{cAB}$ & $45.00 \pm 30.06 \mathrm{cAB}$ \\
Other $^{\mathrm{a}}$ & $1550.50 \pm 217.00 \mathrm{bA}$ & $1301.00 \pm 302.57 \mathrm{bA}$ & $1344.00 \pm 137.43 \mathrm{bA}$ & $1822.25 \pm 227.83 \mathrm{bA}$ \\
\hline
\end{tabular}

Different uppercase letters denote significant differences $(p=0.05)$ in the same row; different lowercase letters denote significant differences $(p=0.05)$ in the same column. TC: control (100 g ground beef only); TCA: $100 \mathrm{~g}$ ground beef+ 100 larvae of Ch. albiceps; TCM: $100 \mathrm{~g}$ ground beef +100 larvae of Ch. megacephala; TCP: $100 \mathrm{~g}$ ground beef +100 larvae of Ch. putoria

${ }^{a}$ Comprises other species of Lucilia, Fanniidae, Muscidae, Piophilidae, and Sarcophagidae 


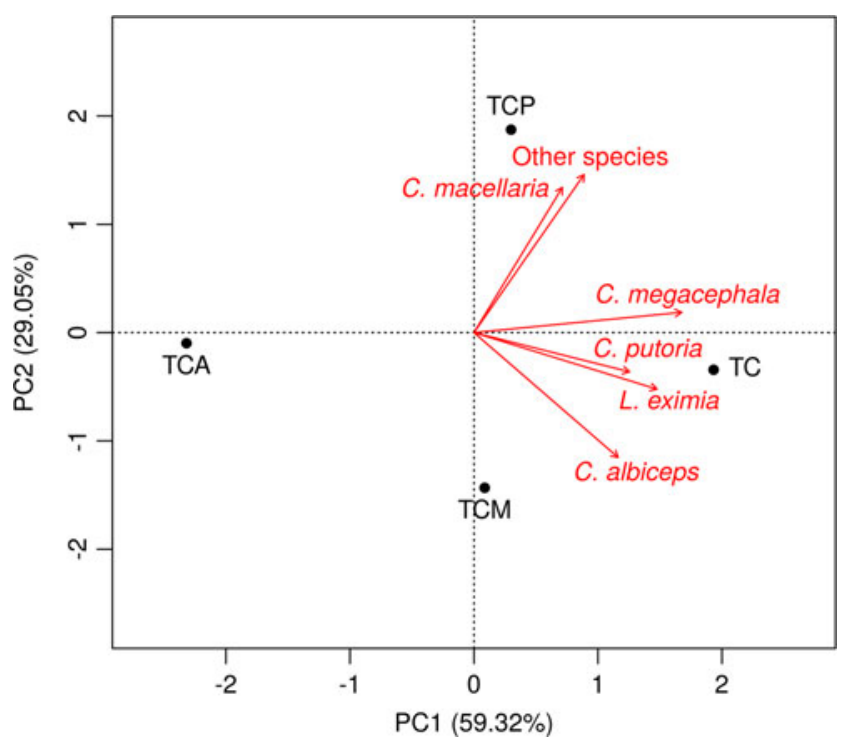

Fig. 2 Biplot of the principal components analysis performed on the data. Principal component 1 explained $59.32 \%$ of the variability of the data; principal component 2 explained $29.05 \%$ of the variability. TC: control (100 g ground beef only); TCA: $100 \mathrm{~g}$ ground beef +100 larvae of C. albiceps; TCM: $100 \mathrm{~g}$ ground beef +100 larvae of C. megacephala; TCP: $100 \mathrm{~g}$ ground beef +100 larvae of $C$. putoria; other species: comprises other species of Lucilia, Fanniidae, Muscidae, Piophilidae, and Sarcophagidae

rainfall totals varied widely, from 16 to $410.8 \mathrm{~mm}$. Blow flies are generally more abundant in favorable environmental conditions (e.g., temperature, humidity, rainfall) (Zabala et al. 2014).

Because heavy rainfall can restrict the flight of blow flies and consequently unfavorably affect the colonization of remains (Ngoen-klan et al. 2011; George et al. 2013), the fluctuations in rainfall during our study should be taken into account. During an investigation on the initial oviposition and development of blow flies infesting rabbit carrion in Malaysia, Mahat et al. (2009) concluded that rain delayed initial oviposition by $1-2$ days and prolonged the pupation period by $1-$ 3 days.

We are aware that using small quantities of decomposing material in medicolegal entomology experiments may cause considerable biases, in contrast to using an entire carcass. However, these small portions of carrion are suitable surrogates to reproduce the ecological interactions that occur among the early dipteran colonizers of a carcass or corpse (Farinha et al. 2014; Oliveira et al. 2015). In addition, we believe that our method, which allows for the occurrence of oviposition in the field, represents an improvement over the laboratory approach to the study of intraguild predation in blow flies.

Oviposition behavior in blow flies has a special significance for the community of flies exploiting carcasses because the patch occupancy by different species visiting the substrate seems to be influenced by the previous presence of congeneric and non-congeneric species. This behavioral attribute certainly influences the distribution of species in different substrates, making the ecological succession dependent on the species of flies that arrive first on corpses. It follows that the prevalence of species on corpses, even though this prevalence largely depends on the relative abundance of the local species, may also be substantially influenced by the ability of the species to detect the presence of other species, mainly predators.

The oviposition preference of female blow flies affects the estimates of the minimum postmortem interval, by delaying or hastening egg laying (Yang and Shiao 2012). Ecological interactions, such as competition and predation, which may affect the development of insects and their populations (Hanski 1987; Rezende et al. 2014), may result in misinterpretations of a crime scene, by causing the exclusion of a given species from a corpse, for example. These interactions should therefore be considered when assessing the minimum postmortem interval since a given species, belonging to the group of first colonizers of carrion, may have been predated by Ch. albiceps. Then, a forensic entomologist should know in advance the behaviors of the local species and should factor the possibility of occurrence of intraguild relationships in by conducting succession experiments.

Acknowledgments T.C.M. and R.A.M. are currently supported by a scholarship from FAPESP (São Paulo Research Foundation), grants 2012/02027-0 and 2014/03310-3, respectively. L.A.G. was supported by FAPESP, grant 2006/55075-1.

\section{Compliance with ethical standards}

Conflict of interest The authors declare that they have no competing interests.

\section{References}

Abdel-Hafeez EH, Mohamed RM, Belal US, Atiya AM, Takamoto M, Aosai F (2015) Human wound myiasis caused by Phormia regina and Sarcophaga haemorrhoidalis in Minia Governorate, Egypt. Parasitol Res 114:3703-3709

Benecke M (2008) A brief survey of the history of forensic entomology. Acta Biologica Benrodis 14:15-38

Cunha AR, Martins D (2009) Classificação climática para os municípios de Botucatu e São Manuel, SP. Irriga 14:1-11

Demétrio CGB, Hinde J, Moral RA (2014) Models for overdispersed data in entomology. In: Ferreira CP, Godoy WAC (eds) Ecological modelling applied to entomology. Springer, Cham, pp 219-259

El-Tantawy NL (2015) Helminthes and insects: maladies or therapies. Parasitol Res 114:359-377

Faria LDB, Orsi L, Trinca LA, Godoy WAC (1999) Larval predation by Chrysomya albiceps on Cochliomyia macellaria, Chrysomya megacephala and Chrysomya putoria. Entomol Exp Appl 90:149155

Faria LDB, Trinca LA, Godoy WAC (2004) Cannibalistic behavior and functional response in Chrysomya albiceps (Diptera: Calliphoridae). J Insect Behav 17:251-261 
Farinha A, Dourado CG, Centeio N, Oliveira AR, Dias D, Rebelo MT (2014) Small bait traps as accurate predictors of dipteran early colonizers in forensic studies. J Insect Sci. doi:10.1673/031.014.77

George KA, Archer MS, Toop T (2013) Abiotic environmental factors influencing blowfly colonization patterns in the field. Forensic Sci Int 229:100-107

Gião JZ, Godoy WAC (2007) Ovipositional behavior in predator and prey blowflies. J Insect Behav 20:77-86

Grassberger M, Friedrich E, Reiter C (2003) The blowfly Chrysomya albiceps (Wiedemann) (Diptera: Calliphoridae) as a new indicator in Central Europe. Int J Legal Med 117:75-81

Guimarães JH, Prado AP, Linhares AX (1978) Three newly introduced blowfly species in Southern Brazil (Diptera: Calliphoridae). Rev Bras Entomol 22:53-60

Hanski I (1987) Carrion fly community dynamics: patchiness, seasonality and coexistence. Ecol Entomol 12:257-266

Linhares AX (1988) The gonotrophic cycle of Chrysomya megacephala (Diptera, Calliphoridae) in the laboratory. Rev Bras Entomol 32: 383-392

Mahat NA, Zafarina Z, Jayaprakash PT (2009) Influence of rain and malathion on the oviposition and development of blowflies (Diptera: Calliphoridae) infesting rabbit carcasses in Kelantan, Malaysia. Forensic Sci Int 192:19-28

Mello RP (2003) Chave para identificação das formas adultas das espécies da família Calliphoridae (Diptera, Brachycera, Cyclorrhapha) encontradas no Brasil. Entomol Vect 10:255-268

Moretti TC, Godoy WAC (2013) Spatio-temporal dynamics and preference for type of bait in necrophagous insects, particularly native and introduced blow flies (Diptera: Calliphoridae). J Med Entomol 50: 415-424

Moretti TC, Ribeiro OB, Thyssen PJ, Solis DR (2008) Insects on decomposing carcasses of small rodents in a secondary forest in Southeastern Brazil. Eur J Entomol 105:691-696

Nassu MP, Thyssen PJ, Linhares AX (2014) Developmental rate of immatures of two fly species of forensic importance: Sarcophaga (Liopygia) ruficornis and Microcerella halli (Diptera: Sarcophagidae). Parasitol Res 113:217-222

Ngoen-klan R, Moophayak K, Klong-klaew T, Irvine KN, Sukontason KL, Prangkio C, Somboon P, Sukontason K (2011) Do climatic and physical factors affect populations of the blow fly Chrysomya megacephala and house fly Musca domestica? Parasitol Res 109: $1279-1292$

Oliveira TC, Vasconcelos SD (2010) Insects (Diptera) associated with cadavers at the Institute of Legal Medicine in Pernambuco, Brazil: implications for forensic entomology. Forensic Sci Int 198:97-102

Oliveira DL, Soares TF, Vasconcelos SD (2015) Effect of bait decomposition on the attractiveness to species of Diptera of veterinary and forensic importance in a rainforest fragment in Brazil. Parasitol Res (pp 1-7, first online: 07 November 2015)

Polis GA, Myers CA, Holt RD (1989) The ecology and evolution of intraguild predation: potential competitors that eat each other. Annu Rev Ecol Evol Syst 20:297-330

Pujol-Luz JR, Marques H, Rodrigues AU, Rafael JA, Santana FHA, Arantes LC, Constantino R (2006) A forensic entomology case from the Amazon rain forest of Brazil. J Forensic Sci 51:1151-1153
R Core Team (2015) R: a language and environment for statistical computing. R Foundation for Statistical Computing, Vienna, URL http:// www.R-project.org

Reibe S, Doetinchem P, Madea B (2010) A new simulation-based model for calculating post-mortem intervals using developmental data for Lucilia sericata (Diptera: Calliphoridae). Parasitol Res 107:9-16

Rezende F, Alonso MA, Souza CM, Thyssen PJ, Linhares AX (2014) Developmental rates of immatures of three Chrysomya species (Diptera: Calliphoridae) under the effect of methylphenidate hydrochloride, phenobarbital, and methylphenidate hydrochloride associated with phenobarbital. Parasitol Res 113:1897-1907

Root R (1967) The niche exploitation pattern of the blue-grey gnatcatcher. Ecol Monogr 37:317-350

Rosa GS, Carvalho LR, Godoy WAC (2004) Survival rate, body size and food abundance in pure and mixed blowfly cultures. Afr Entomol 12:97-105

Rosa GS, Carvalho LR, Reis SF, Godoy WAC (2006) The dynamics of intraguild predation in Chrysomya albiceps (Diptera: Calliphoridae): interactions between instars and species under different abundances of food. Neotrop Entomol 35:775-780

Serbino NMB, Godoy WAC (2007) Seasonal abundance and distribution of necrophagous Diptera in western São Paulo state, Brazil. Func Ecosyst Commun 1:145-149

Silva ICR, Mancera PFA, Godoy WAC (2003) Population dynamics of Lucilia eximia (Diptera: Calliphoridae). J Appl Entomol 127:2-6

Souza AM, Linhares AX (1997) Diptera and Coleoptera of potential forensic importance in southeastern Brazil: relative abundance and seasonality. Med Vet Entomol 11:8-12

Thyssen PJ, Souza CM, Shimamoto PM, Salewski TB, Moretti TC (2014) Rates of development of immatures of three species of Chrysomya (Diptera: Calliphoridae) reared in different types of animal tissues: implications for estimating the postmortem interval. Parasitol Res 113:3373-3380

Tomberlin JK, Mohr R, Benbow ME, Tarone AM, VanLaerhoven S (2011) A roadmap for bridging basic and applied research in forensic entomology. Annu Rev Entomol 56:401-421

Wells J (1991) Chrysomya megacephala (Diptera: Calliphoridae) has reached the continental United States: review of its biology, pest status, and spread around the world. J Med Entomol 28:471-473

Wolff M, Uribe A, Ortiz A, Duque P (2001) A preliminary study of forensic entomology in Medellín, Colombia. Forensic Sci Int 120:53-59

Yang LH (2006) Periodical cicadas use light for oviposition site selection. Proc R Soc B 273:2993-3000

Yang ST, Shiao SF (2012) Oviposition preferences of two forensically important blow fly species, Chrysomya megacephala and C. rufifacies (Diptera: Calliphoridae), and implications for postmortem interval estimation. J Med Entomol 49:424-435

Zabala J, Días B, Saloña-Bordas MI (2014) Seasonal blowfly distribution and abundance in fragmented landscapes. Is it useful in forensic inference about where a corpse has been decaying? PLoS ONE. doi:10.1371/journal.pone.0099668

Zhang D, Liu XH, Li XY, Zhang M, Li K (2013) Antennal sensilla of the green bottle fly, Lucilia sericata (Meigen) (Diptera: Calliphoridae). Parasitol Res 112:3843-3850 